\title{
Ciência e Tecnologia
}

Para o Desenvolvimento

Ambiental, Cultural

e Socioeconômico

Leinig Antonio Perazolli

(organizador) 


\section{Ciência e Tecnologia}

Para o Desenvolvimento

Ambiental, Cultural

e Socioeconômico

Leinig Antonio Perazolli

(organizador) 


\section{1 by Editora Artemis \\ Copyright (C) Editora Artemis \\ Copyright do Texto (C) 2021 Os autores \\ Copyright da Edição (C) 2021 Editora Artemis}

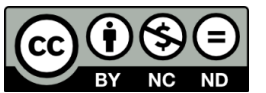

O conteúdo deste livro está licenciado sob uma Licença de Atribuição Creative Commons Atribuição-Não-Comercial NãoDerivativos 4.0 Internacional (CC BY-NC-ND 4.0). Direitos para esta edição cedidos à Editora Artemis pelos autores. Permitido o download da obra e o compartilhamento, desde que sejam atribuídos créditos aos autores, e sem a possibilidade de alterá-la de nenhuma forma ou utilizá-la para fins comerciais.

A responsabilidade pelo conteúdo dos artigos e seus dados, em sua forma, correção e confiabilidade é exclusiva dos autores. A Editora Artemis, em seu compromisso de manter e aperfeiçoar a qualidade e confiabilidade dos trabalhos que publica, conduz a avaliação cega pelos pares de todos manuscritos publicados, com base em critérios de neutralidade e imparcialidade acadêmica.

$\begin{array}{ll}\text { Editora Chefe } & \text { Profa Dra Antonella Carvalho de Oliveira } \\ \text { Editora Executiva } & \text { M. a Viviane Carvalho Mocellin } \\ \text { Direção de Arte } & \text { M. a Bruna Bejarano } \\ \text { Diagramação } & \text { Elisangela Abreu } \\ \text { Organizador } & \text { Prof. Dr. Leinig Antonio Perazolli } \\ \text { Imagem da Capa } & \text { peacestock/123RF } \\ \text { Bibliotecário } & \text { Maurício Amormino Júnior - CRB6/2422 }\end{array}$

\section{Conselho Editorial}

Prof.a Dr.a Ada Esther Portero Ricol, Universidad Tecnológica de La Habana "José Antonio Echeverría", Cuba

Prof. Dr. Adalberto de Paula Paranhos, Universidade Federal de Uberlândia

Prof.a Dr.a Amanda Ramalho de Freitas Brito, Universidade Federal da Paraíba

Prof. a Dr.a Ana Clara Monteverde, Universidad de Buenos Aires, Argentina

Prof. Dr. Ángel Mujica Sánchez, Universidad Nacional del Altiplano, Peru

Prof.a Dr.a Angela Ester Mallmann Centenaro, Universidade do Estado de Mato Grosso

Prof.a Dr.a Begoña Blandón González, Universidad de Sevilla, Espanha

Prof. a Dr.a Carmen Pimentel, Universidade Federal Rural do Rio de Janeiro

Prof. a Dr.a Catarina Castro, Universidade Nova de Lisboa, Portugal

Prof.a Dr.a Cláudia Padovesi Fonseca, Universidade de Brasília-DF

Prof.a Dr.a Cláudia Neves, Universidade Aberta de Portugal

Prof. Dr. Cleberton Correia Santos, Universidade Federal da Grande Dourados

Prof. Dr. David García-Martul, Universidad Rey Juan Carlos de Madrid, Espanha

Prof.a Dr.a Deuzimar Costa Serra, Universidade Estadual do Maranhão

Prof. a Dr.a Eduarda Maria Rocha Teles de Castro Coelho, Universidade de Trás-os-Montes e Alto Douro, Portugal

Prof. Dr. Eduardo Eugênio Spers, Universidade de São Paulo

Prof. Dr. Eloi Martins Senhoras, Universidade Federal de Roraima

Prof.a Dr.a Elvira Laura Hernández Carballido, Universidad Autónoma del Estado de Hidalgo, México

Prof. a Dr.a Emilas Darlene Carmen Lebus, Universidad Nacional del Nordeste/ Universidad Tecnológica Nacional, Argentina

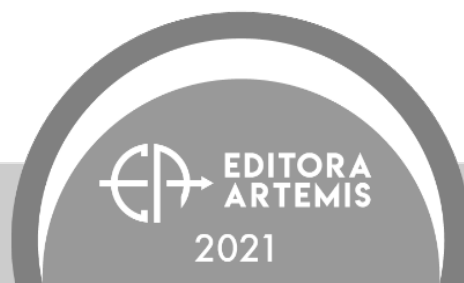


Prof. a Dr. a Erla Mariela Morales Morgado, Universidad de Salamanca, Espanha

Prof. Dr. Ernesto Cristina, Universidad de la República, Uruguay

Prof. Dr. Ernesto Ramírez-Briones, Universidad de Guadalajara, México

Prof. Dr. Gabriel Díaz Cobos, Universitat de Barcelona, Espanha

Prof. Dr. Geoffroy Roger Pointer Malpass, Universidade Federal do Triângulo Mineiro

Prof.a Dr.a Gladys Esther Leoz, Universidad Nacional de San Luis, Argentina

Prof.a Dr.a Glória Beatriz Álvarez, Universidad de Buenos Aires, Argentina

Prof. Dr. Gonçalo Poeta Fernandes, Instituto Politécnido da Guarda, Portugal

Prof. Dr. Gustavo Adolfo Juarez, Universidad Nacional de Catamarca, Argentina

Prof.a Dr.a Iara Lúcia Tescarollo Dias, Universidade São Francisco

Prof. a Dr.a Isabel del Rosario Chiyon Carrasco, Universidad de Piura, Peru

Prof.a Dr.a Isabel Yohena, Universidad de Buenos Aires, Argentina

Prof. Dr. Ivan Amaro, Universidade do Estado do Rio de Janeiro

Prof. Dr. Iván Ramon Sánchez Soto, Universidad del Bío-Bío, Chile

Prof. a Dr. a Ivânia Maria Carneiro Vieira, Universidade Federal do Amazonas

Prof. Me. Javier Antonio Albornoz, University of Miami and Miami Dade College, USA

Prof. Dr. Jesús Montero Martínez, Universidad de Castilla - La Mancha, Espanha

Prof. Dr. João Manuel Pereira Ramalho Serrano, Universidade de Évora, Portugal

Prof. Dr. Joaquim Júlio Almeida Júnior, UniFIMES - Centro Universitário de Mineiros

Prof. Dr. Juan Carlos Mosquera Feijoo, Universidad Politécnica de Madrid, Espanha

Prof. Dr. Juan Diego Parra Valencia, Instituto Tecnológico Metropolitano de Medellín, Colômbia

Prof. Dr. Júlio César Ribeiro, Universidade Federal Rural do Rio de Janeiro

Prof. Dr. Leinig Antonio Perazolli, Universidade Estadual Paulista

Prof.a Dr.a Lívia do Carmo, Universidade Federal de Goiás

Prof. a Dr.a Luciane Spanhol Bordignon, Universidade de Passo Fundo

Prof. Dr. Luis Vicente Amador Muñoz, Universidad Pablo de Olavide, Espanha

Prof. a Dr.a Macarena Esteban Ibáñez, Universidad Pablo de Olavide, Espanha

Prof. Dr. Manuel Ramiro Rodriguez, Universidad Santiago de Compostela, Espanha

Prof. Dr. Marcos Augusto de Lima Nobre, Universidade Estadual Paulista

Prof. Dr. Marcos Vinicius Meiado, Universidade Federal de Sergipe

Prof.a Dr. a Mar Garrido Román, Universidad de Granada, Espanha

Prof. a Dr.a Margarida Márcia Fernandes Lima, Universidade Federal de Ouro Preto

Prof. a Dr. a Maria Aparecida José de Oliveira, Universidade Federal da Bahia

Prof.a Dr. a Maria do Céu Caetano, Universidade Nova de Lisboa, Portugal

Prof. a Dr. a Maria do Socorro Saraiva Pinheiro, Universidade Federal do Maranhão

Prof.a Dr.a Maria Lúcia Pato, Instituto Politécnico de Viseu, Portugal

Prof. a Dr. a Maritza González Moreno, Universidad Tecnológica de La Habana "José Antonio Echeverría", Cuba

Prof.a Dr. a Mauriceia Silva de Paula Vieira, Universidade Federal de Lavras

Prof. a Dr. a Odara Horta Boscolo, Universidade Federal Fluminense 
Prof.a Dr.a Patrícia Vasconcelos Almeida, Universidade Federal de Lavras Prof. a Dr. a Paula Arcoverde Cavalcanti, Universidade do Estado da Bahia Prof. Dr. Rodrigo Marques de Almeida Guerra, Universidade Federal do Pará Prof. Dr. Saulo Cerqueira de Aguiar Soares, Universidade Federal do Piauí Prof. Dr. Sergio Bitencourt Araújo Barros, Universidade Federal do Piauí Prof. Dr. Sérgio Luiz do Amaral Moretti, Universidade Federal de Uberlândia Prof. a Dr. a Silvia Inés del Valle Navarro, Universidad Nacional de Catamarca, Argentina Prof. a Dr. - Teresa Cardoso, Universidade Aberta de Portugal Prof. a Dr. a Teresa Monteiro Seixas, Universidade do Porto, Portugal

Prof. Dr. Turpo Gebera Osbaldo Washington, Universidad Nacional de San Agustín de Arequipa, Peru Prof. Dr. Valter Machado da Fonseca, Universidade Federal de Viçosa Prof. a Dr.a Vanessa Bordin Viera, Universidade Federal de Campina Grande Prof. a Dr. a Vera Lúcia Vasilévski dos Santos Araújo, Universidade Tecnológica Federal do Paraná Prof. Dr. Wilson Noé Garcés Aguilar, Corporación Universitaria Autónoma del Cauca, Colômbia

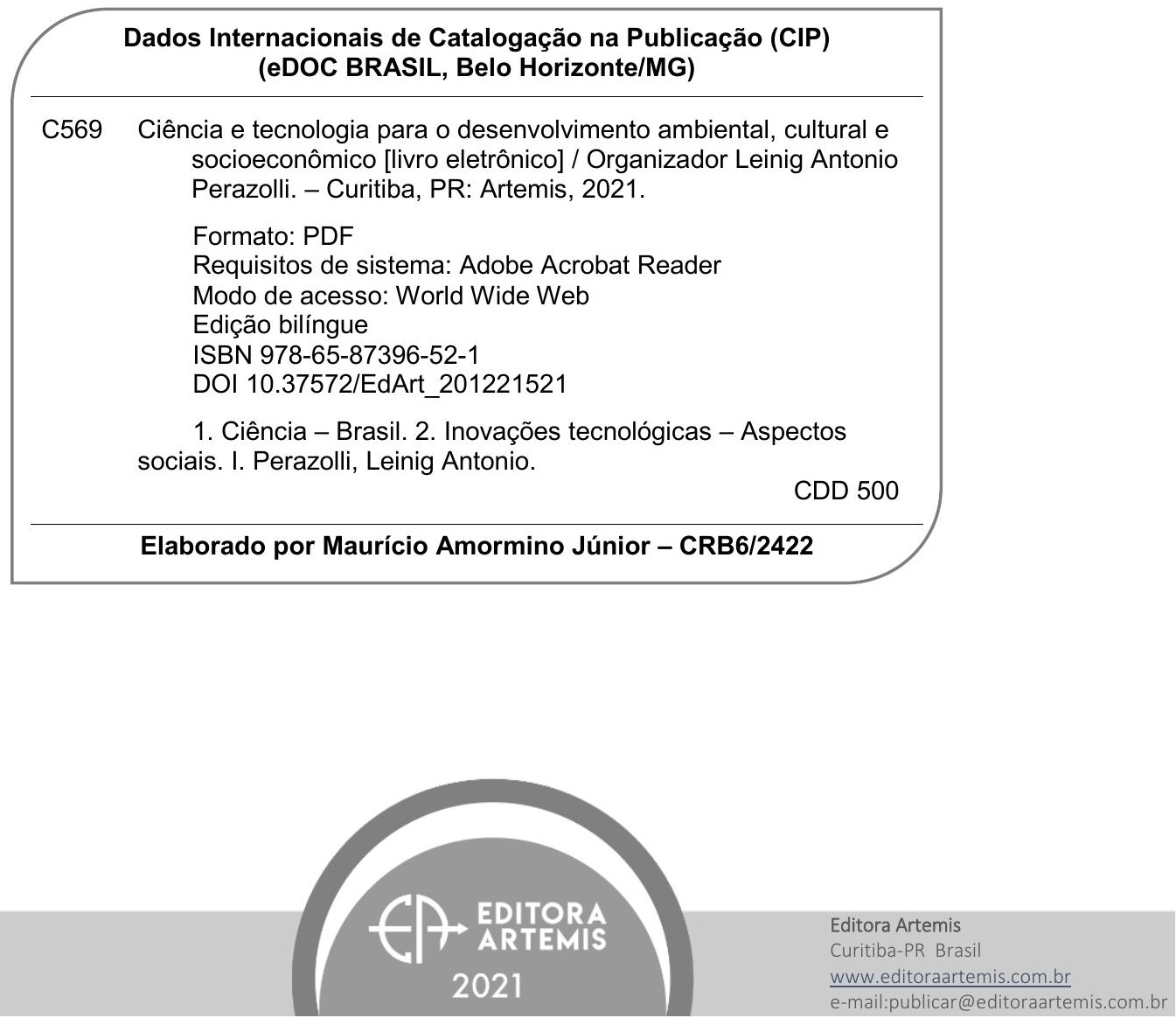




\section{APRESENTAÇÃO}

\section{A publicação intitulada "Ciência e Tecnologia para o Desenvolvimento}

Ambiental, Cultural e Socioeconômico" faz uma coletânea de resultados científicos, em diferentes áreas do conhecimento, exemplificando um modelo para a abordagem dos problemas relacionados ao desenvolvimento ambiental, cultural e socioeconômico da sociedade atual.

A obra se justifica ao apresentar caminhos para se atingir soluções positivas frente às grandes e variadas dificuldades que estamos observando nas últimas décadas, decorrentes de ações comerciais, do desejo de consumo e ao fato que as fontes são finitas, porém os desejos humanos não. Estas ações comerciais levam à destruição ambiental, massificação cultural e a problemas socioeconômicos devido à diferença de renda e ao aumento da frequência de desastres ambientais, os quais geram grandes prejuízos financeiros e humanos.

A obra se inicia relatando o estado da arte sobre o consumo ético, avança para a descrição da vulnerabilidade e do emprego sustentável de ecossistemas. Destaca a função dos processos de educação, peça fundamental para a evolução sustentável de qualquer sociedade e a importância da interrelação entre os municípios de diferentes países para a busca de objetivos comuns.

$\mathrm{Na}$ continuidade temos exemplos de resultados científicos positivos para o uso de tecnologias em diferentes áreas do conhecimento, desde o uso de micro-organismos e sementes para a produção de óleos e energia, tratamentos e recuperação de resíduos de minerais e propostas científicas avançadas nas áreas de separação líquido-líquido, magneto eletrônica e varistores. A obra também ilustra as consequências das ações negativas praticadas pela ação humana. Cabe destacar que se estas ações não forem evitadas, corrigidas e/ou readequadas as consequências dos desastres ambientais, com reflexos negativos em todas as áreas, poderão se tornar irreversíveis em questão de décadas.

A importância deste livro reside ao indicar caminhos para fomentar o desenvolvimento ambiental, cultural e socioeconômico de forma sustentável.

Quero externar meus sinceros agradecimentos aos autores dos trabalhos científicos e à Editora Artemis, pela organização desta obra.

Prof. Dr. Leinig Antonio Perazolli UNESP - Instituto de Química de Araraquara/SP 
CAPÍTULO 1

ESTADO DEL ARTE SOBRE CONSUMO ÉTICO EN LA ÚLTIMA DÉCADA: REVISIÓN SISTEMÁTICA DE LA LITERATURA

Javier Solano

David Zaldumbide Peralvo

Delia García Vences

dø) https://doi.org/10.37572/EdArt_2012215211

CAPÍTULO 2. 18

VULNERABILIDAD DE LAS AGUAS SUBTERRÁNEAS A LA CONTAMINACIÓN POR NITRATO EN LA CUENCA DEL RÍO EBRO (ESPAÑA) MEDIANTE EL PROCEDIMIENTO LU-IV

Mercedes Arauzo Sánchez

María Valladolid Martín

Gema García González

doi)'https://doi.org/10.37572/EdArt_2012215212

CAPÍTULO 3. 36

ECOSISTEMAS DE EMPRENDIMIENTO, DE LO NACIONAL A LO REGIONAL, SANTANDER UNA APUESTA

Mónica María Pacheco Valderrama

Olga Cecilia Alarcón Vesga

do) https://doi.org/10.37572/EdArt_2012215213

CAPÍTULO 4 47

O ENSINO MÉDIO POLITÉCNICO E A REALIDADE TECNOLÓGICA VIVENCIADA PELOS ALUNOS E PROFESSORES EM DUAS ESCOLAS DE PELOTAS- RS

Elis Regina Madeira da Porciúncula

Marcos Antonio Anciuti

doi) https://doi.org/10.37572/EdArt_2012215214 
UNIVERSIDADES Y LA APROPIACIÓN SOCIAL DE LA CIENCIA. ANÁLISIS DEL SISTEMA DE CIENCIA Y TECNOLOGÍA DE CHILE

Juan Ramón Contreras González

doi)'https://doi.org/10.37572/EdArt_2012215215

CAPÍTULO 6 89

COMPARACIÓN DE LA NORMATIVA DE CONTROL INTERNO Y EXTERNO MUNICIPAL ENTRE ECUADOR Y ARGENTINA

Verónica Ponce

Carlos Albert Ferreira

José Townsend

doi) $h$ ttps://doi.org/10.37572/EdArt_2012215216

CAPÍTULO 7 103

EL USO DE LA BIOMASA DEL HONGO Aspergillus niger PARA LA ELIMINACIÓN DE METALES PESADOS DE AGUAS CONTAMINADAS

Ismael Acosta Rodríguez

Nancy Pacheco Castillo

Adriana Rodríguez Pérez

Juan Fernando Cárdenas González

Víctor Manuel Martínez Juárez

Francisco Navarro Castillo

Erika Enríquez Domínguez

Juana Tovar Oviedo

doi) https://doi.org/10.37572/EdArt_2012215217

CAPÍTULO 8. 114

INFLUENCIA DE LA ENVOLVENTE CON BAJOS NIVELES DE TRANSMITANCIA EN EL CONSUMO ENERGÉTICO DE VIVIENDAS EN CLIMAS CÁLIDOS

María Victoria Mercado

Celina Filippín

Gustavo Barea

doi) https://doi.org/10.37572/EdArt_2012215218 
ESTUDIO DE LA ACTIVIDAD ANTIMICROBIANA DE LA CUPRITA SINTETIZADA POR RUTA QUÍMICA

Orfelinda Avalo Cortez

David Pedro Martínez Aguilar

doi) $h$ https://doi.org/10.37572/EdArt_2012215219

CAPÍTULO 10. 147

ACEITE DE LA SEMILLA DE AGUACATE, UNA REVISIÓN DESDE SUS POTENCIALIDADES

Lina González Asías

Amelia Espitia Arrieta

Jennifer Lafont Mendoza

do) https://doi.org/10.37572/EdArt_20122152110

\section{CAPÍTULO 11}

ESTUDIOS QUÍMICOS REALIZADOS A LA SEMILLA DE Moringa oleifera Lam Y SU IMPACTO EN LA SALUD HUMANA: UNA REVISIÓN TEÓRICA

Jennifer Lafont Mendoza

William Negrete Humanez

Amelia Espitia Arrieta

do)'https://doi.org/10.37572/EdArt_20122152111

CAPÍTULO 12. 171

ZONAS DE INFLUENCIA GENERADAS POR PROPIEDADES FISICAS PARA LA CARACTERIZACION EN CAMPO DEL MATERIAL ROCOSO

Ernesto Patricio Feijoo Calle

Andrés Nicolás Aguirre Larriva

Bernardo Andrés Feijoo Guevara

do)'https://doi.org/10.37572/EdArt_20122152112

CAPÍTULO 13 186

CARACTERIZACIÓN Y FLOTACIÓN DE APATITA CONTENIDAS EN RELAVE DE HIERRO

Luis Valderrama

Mario Santander

Osvaldo Gómez 
Patricia Tapia

Patricio Muñoz

Bruno Zazzali

doi)https://doi.org/10.37572/EdArt_20122152113

\section{CAPÍTULO 14}

ESTUDO DE COMPÓSITOS COM MATRIZ DE ALUMÍNIO E RESÍDUOS DE MINÉRIO DE MANGANÊS POR SINTERIZAÇÃO AO AR NATURAL

Affonso Henrique Alves Ribeiro

Margarida Márcia Fernandes Lima

Rhelman Rossano Urzedo Queiroz

Rosa Malena Fernandes Lima

do) https://doi.org/10.37572/EdArt_20122152114

CAPÍTULO 15 214

EXTRAÇÃO LÍQUIDO-LÍQUIDO APLICADA AO PROCESSO DE REFINO DE ETANOL COMBUSTIVELL

Gabriel Manso Kozlowski Pitombeira

Leinig Antonio Perazolli

Elias de Souza Monteiro Filho

do)'https://doi.org/10.37572/EdArt_20122152115

CAPÍTULO 16.

EVIDENCING THE MAGNETOELECTRIC COUPLING IN BI1-XNDXFEO3 COMPOSITIONS THROUGH FERROIC CHARACTERIZATIONS

Anuar Jose Mincache

Lilian Felipe da Silva Tupan

Odair Gonçalves de Oliveira

Ivair Aparecido dos Santos

Luiz Fernando Cótica

do)'https://doi.org/10.37572/EdArt_20122152116

CAPÍTULO 17.

EFEITO DO COBALTO E ZINCO EM VARISTORES À BASE DE SNO

Glauco Meireles Mascarenhas Morandi Lustosa

João Paulo de Campos da Costa

Leinig Antônio Perazzoli

Biljana Stojanovic 
Maria Aparecida Zaghete Bertochi

Elson Longo

doi)'https://doi.org/10.37572/EdArt_20122152117

CAPÍTULO 18 250

GRADUAÇÃO HISTOLÓGICA DOS GLIOMAS PELA ANÁLISE DA PERMEABILIDADE MICROVASCULAR POR RESSONÂNCIA MAGNÉTICA

Pedro Henrique Raffa de Souza

Rodrigo de Oliveira Plotze

Lucas Giansante Abud

Carolina Baraldi Araújo Restini

do)' https://doi.org/10.37572/EdArt_20122152118

CAPÍTULO 19. 270

MONITORAMENTO DE ENCALHES DE ANIMAIS MARINHOS NA GESTÃO DA PESCA EM UNIDADES DE CONSERVAÇÃO

Viviane Korres Bisch

Roberto Sforza

do)'https://doi.org/10.37572/EdArt_20122152119

SOBRE O ORGANIZADOR. 280

ÍNDICE REMISSIVO 


\section{COMPARACIÓN DE LA NORMATIVA DE CONTROL INTERNO Y EXTERNO MUNICIPAL ENTRE ECUADOR Y ARGENTINA}

Data de submissão: 30/09/2021

Data de aceite: 18/10/2021

Verónica Ponce

Magister en Administración de Empresas

Docente Titular Investigadora en

Grado y Postgrado de la

Facultad de Ciencias Administrativas

Universidad Estatal

Península de Santa Elena

Santa Elena, Ecuador

https://orcid.org/0000-0002-2038-2654

Carlos Albert Ferreira

Doctor en Ciencias de la Administración

Profesor Asociado

Dedicación Exclusiva ordinario

Contabilidad Pública y

Administración Pública

Docente Investigador

Categorizado en el Programa de

Incentivos a Docentes Investigadores

Departamento de Ciencias de la

Administración

Universidad Nacional del Sur

Bahía Blanca, Argentina

https://orcid.org/0000-0003-2479-6288
RESUMEN: El presente artículo tiene por objeto realizar un análisis comparativo de la normativa vigente en Ecuador y Argentina fundamentado en la construcción de un panorama legal que permita identificar los elementos más significativos que se aplican en el control interno de los Municipios. Se utilizó el método comparativo para contrastar las principales características sobre los marcos legales y el uso de información documental de fuentes secundarias. Los resultados se miden en dos enfoques: mejoras en los estándares de control interno que permiten hacer análisis preventivos y correctivos y cambios profundos en la normativa legal vigente, es importante que los gobiernos locales lleven a cabo revisiones de su normativa ajustadas a las entidades de control en su fiel cumplimiento.

PALABRAS CLAVE: Análisis. Normas. Control Interno. Municipios locales. 


\section{INTRODUCCIÓN}

Para algunos países de América Latina la grave crisis financiera, política y hasta moral lleva consigo un problema de fondo, que se profundiza cada vez más por la gestión de cada Gobierno de turno, independientemente a la idea política a la que pertenezca. En muchos casos, parten del principio que, la modificación periódica de la Constitución les permite gobernar en armonía a sus ideologías y principios. Es imposible pensar en un desarrollo económico y el lineamiento de objetivos a partir de diferentes doctrinas políticas que cada vez más limitan la soberanía de los pueblos. El análisis que realizan (Gismano, Ferreira, Aispuro, Scoponi, \& Iriarti, 2019) se hace necesaria una legislación con reglas y principios claros que marquen el camino a mejorar los controles en los diferentes ámbitos de la cosa pública, pero se refieren a países denominados como del primer mundo, y continúan "en varios países se ha avanzado en el tema. Así es que, en España, miembro de la Unión Europea, las políticas de Gobierno Abierto, acceso a la información pública, y acciones y herramientas de control (interno y externo) están ya muy desarrolladas".

Para (The Dialogue, 2016) "El asunto es relevante porque muchas de las reformas políticas que se hacen en América Latina son una especie de frazada de retazos en la cual las partes aparecen anexadas en forma contradictoria y donde todo está pensado para resolver problemas de coyuntura". Se deben comparar las diferencias en cada una de las experiencias entre Ecuador y Argentina en las regiones donde toma fuerza este análisis jurídico.

Para centrarnos en el estudio, se toman como referencia a los Gobiernos Locales de Argentina y Ecuador, donde se sabe que la legislación reconoce el principio de Autonomía de los mencionados Gobiernos.

En Argentina, de acuerdo con su Constitución Nacional, en el Art. 123. Dice: "Cada provincia dicta tu propia constitución, conforme a lo dispuesto por el Art. $5^{\circ}$, asegurando la autonomía municipal y reglando su alcance y contenido en el orden institucional, político, administrativo, económico y financiero.

Mientras que, en Ecuador, la Constitución Nacional en su Art. 239. Dice: "El régimen de gobiernos autónomos descentralizados se regirá por la ley correspondiente, que establecerá un sistema nacional de competencias de carácter obligatorio y progresivo y definirá las políticas y mecanismos para compensar los desequilibrios territoriales en el proceso de desarrollo. (Estudio Comparativo de las leyes de Régimen Local, 2011).

En el caso de Argentina los elementos determinantes de la competencia municipal es su poder jurídico, representado por el grado de autonomía que establece cada 
provincia. Una condición de este poder es el tamaño del gobierno local que posea, y por las constituciones provinciales que, en la mayor parte de los casos, establecen atribuciones y estructuras organizativas diferentes entre sí. Las Constituciones Provinciales consideran distintas categorias y niveles a los municipios. Son consideradas como distintos "niveles" de gobierno local, la cantidad de categorías de municipios y las restantes formas de gobierno local, la diferenciación radica en la población y las formas de gobierno local vigentes en la actualidad.

Las categorías de municipios se constituyen en uno de los factores de diferenciación que define el derecho de ejercer el poder constituyente. Un municipio habilitado o competente para dictarse su carta orgánica o carta municipal es intrínsecamente distinto del municipio que no tiene ese derecho. Una vez cumplidos los requisitos que lo habilitan (cantidad de habitantes mínimos en la mayor parte de los casos) sólo resta la voluntad política de ejercer dicha atribución. El otro factor de diferenciación es el uso concreto de ese derecho, ya que recién allí se ejercita en plenitud la autonomía institucional. (Iturburu, Mónica Silvana, $20042^{\circ}$ Edición).

El marco normativo varía porque es la Carta Orgánica la norma que regula el funcionamiento municipal, en tanto la Ley Orgánica de las Municipalidades de cada provincia establece el marco regulatorio de los gobiernos locales que no la tienen. Bajo esta perspectiva, son muy escasas las constituciones que conciben una única identidad municipal y aún menos las que prescriben una única forma de gobierno local.

La Constitución de la republica del Ecuador menciona en el Art. 215: "El presupuesto de los gobiernos autónomos descentralizados se ajustará a los planes regionales, provinciales, cantonales y parroquiales respectivamente, en el marco del Plan Nacional de Desarrollo, sin menoscabo de sus competencias y autonomía. $Y$ en su Art. 270. Los gobiernos autónomos descentralizados participarán de las rentas del Estado de conformidad con los principios de subsidiariedad, solidaridad y equidad. (Constitución de la República del Ecuador, 2008). Los Municipios de las ciudades más grandes del Ecuador, Quito, Guayaquil y Cuenca, tienen mayor cantidad de recursos por tener la mayor cantidad de habitantes. Rigen sus actividades por el Código Orgánico de Organización territorial, donde se establece las funciones de todos los municipios, y hace excepción en los municipios grandes de 3 las tres ciudades más grandes, como son Guayaquil, Quito y Cuenca, en cuanto a su presupuesto. (Código Orgánico de Organización Territorial, Autonomía y Descentraliziación de los Gobiernos Autónomos Descentralizados Del Ecuador, 2010) 


\section{ORGANISMOS DE CONTROL Y SUS FUNCIONES}

\subsection{REPÚBLICA DE ECUADOR}

Las entidades que administran recursos municipales requieren revisiones y controles periódicos que se desarrollan mediante exámenes de auditoría que, de acuerdo con la naturaleza de la revisión, podrían clasificarse en: auditorías financieras, de control interno, de gestión, exámenes especiales, entre otras. Estas intervenciones se efectúan en las entidades que integran el sector público, organizado por la Constitución de la República del Ecuador de la siguiente manera:

1. Los organismos y dependencias de las funciones ejecutiva, legislativa, judicial, electoral y de transparencia y control social.

2. Las entidades que integran el régimen autónomo descentralizado.

3. Los organismos y entidades creados por la Constitución o la ley para el ejercicio de la potestad estatal, para la prestación de servicios públicos o para desarrollar actividades económicas asumidas por el Estado.

4. Las personas jurídicas creadas por acto normativo de los gobiernos autónomos descentralizados para la prestación de servicios públicos. (Constitución de la República del Ecuador, 2008)

En Ecuador el control a los recursos públicos se ejecuta mediante auditorías en los diferentes sectores de la administración estatal y en atención a los requerimientos de la entidades y demandas ciudadanas. Los Planes Anuales de Control se formulan y ejecutan en concordancia con los objetivos estratégicos y tácticos del plan estratégico, con sujeción a las disposiciones constitucionales, legales y reglamentarias vigentes.

Se reconoce que toda entidad que administre recursos estatales se encuentra bajo la supervisión del organismo máximo de control, la Contraloría General del Estado, el cual, junto a otras entidades gubernamentales, conforma la sexta función estatal, denominada "control y transparencia social". La CGE "tiene la dirección del sistema de control, fiscalización y auditoría del Estado, así como también, la función de examinar, verificar y evaluar el cumplimiento de la visión, misión y objetivos de las instituciones del Estado en conformidad con la utilización de recursos y bienes públicos" (Asamblea Nacional Constituyente, 2002, p. 7).

En Ecuador, la Contraloría General del Estado es un organismo técnico encargado del control de la utilización de los recursos estatales, y la consecución de los objetivos de las instituciones. Entre las funciones: 
1. Dirigir el sistema de control administrativo que se compone de auditoría interna, auditoría externa y del control interno de las entidades del sector público y de las entidades privadas que dispongan de recursos públicos.

2. Determinar responsabilidades administrativas y civiles culposas e indicios de responsabilidad penal.

\section{Expedir la normativa para el cumplimiento de sus funciones.}

4. Asesorar a los órganos y entidades del Estado cuando se le solicite..

Fuente: Elaboración Propia desde la Constitución del Ecuador Art. 212.

\subsection{REPÚBLICA DE ARGENTINA}

Un eficiente y eficaz sistema de control interno normativo, financiero, económico y de gestión sobre sus propias operaciones, comprendiendo la práctica del control previo y posterior y de la auditoría interna; son procedimientos adecuados que aseguren la conducción económica y eficiente de las actividades institucionales y la evaluación de los resultados de los programas, proyectos y operaciones de los que es responsable la jurisdicción o entidad.

Según la Ley 24.156 de la Administración Financiera y de los Sistemas de control del Sector Público Nacional y su reglamentación Decreto 1344/2007 en su Artículo 7, se establece que la Sindicatura General de la Nación y la Auditoria General de la Nación serán los órganos rectores de los sistemas de control interno y externo, respectivamente.

"Art. 103. El modelo de control que aplique y coordine la sindicatura deberá ser integral e integrado, abarcar los aspectos presupuestarios, económicos, financieros, patrimoniales, normativos y de gestión, la evaluación de programas, proyectos y operaciones y estar fundado en criterios de economía, eficiencia y eficacia."

El actual sistema de control del sector público nacional, diseñado por la Ley de Administración Financiera y de los Sistemas de Control del Sector Público Nacional, Ley 24.156 , ha creado como órgano de control interno del Poder Ejecutivo Nacional a la Sindicatura General de la Nación, SIGEN (artículos 96 y 100) -órgano normativo, de supervisión y coordinación - y a las Unidades de Auditoría Interna (UAI), las cuales dependen jerárquicamente de la autoridad superior de cada organismo, y actúan coordinadas técnicamente por la Sindicatura General de la Nación, en su carácter de órgano rector del control interno. (Iturburu, Mónica Silvana, $20042^{\circ}$ Edición) 
Ilustración 2. El Control, según la división política: Diferencias entre Ecuador y Argentina

\begin{tabular}{|c|c|c|}
\hline $\begin{array}{c}\text { El control externo, según la } \\
\text { división política }\end{array}$ & Ecuador & Argentina \\
\hline Nacional & $\begin{array}{c}\text { Contraloría General del } \\
\text { Estado }\end{array}$ & Auditoría general de la Nación \\
\hline Provincial & $\begin{array}{c}\text { Contraloría General del } \\
\text { Estado }\end{array}$ & $\begin{array}{l}\text { Auditoría General Provincial } \\
\text { Tribunal de Cuentas Provincial }\end{array}$ \\
\hline Municipal & $\begin{array}{c}\text { Contraloría General del } \\
\text { Estado }\end{array}$ & $\begin{array}{l}\text { Tribunal de Cuentas } \\
\text { (Buenos Aires) }\end{array}$ \\
\hline $\begin{array}{c}\text { El control interno, según la } \\
\text { división política }\end{array}$ & Ecuador & Argentina \\
\hline Nacional & $\begin{array}{c}\text { Contraloría General del } \\
\text { Estado }\end{array}$ & Sindicatura General de la Nación \\
\hline Provincial & $\begin{array}{c}\text { Contraloría General del } \\
\text { Estado }\end{array}$ & $\begin{array}{l}\text { Contaduría General de la Provincia } \\
\text { (Provincia de Buenos Aires) }\end{array}$ \\
\hline Municipal & $\begin{array}{c}\text { Contraloria General del } \\
\text { Estado }\end{array}$ & $\begin{array}{c}\text { Contador Municipal } \\
\text { (Provincia de Buenos Aires) }\end{array}$ \\
\hline
\end{tabular}

Fuente: Elaboración propia, tomada de las Constituciones y Leyes orgánicas de Ecuador y Argentina.

Ilustración 3. El Control, Diferencias y similitudes entre Ecuador y Argentina.

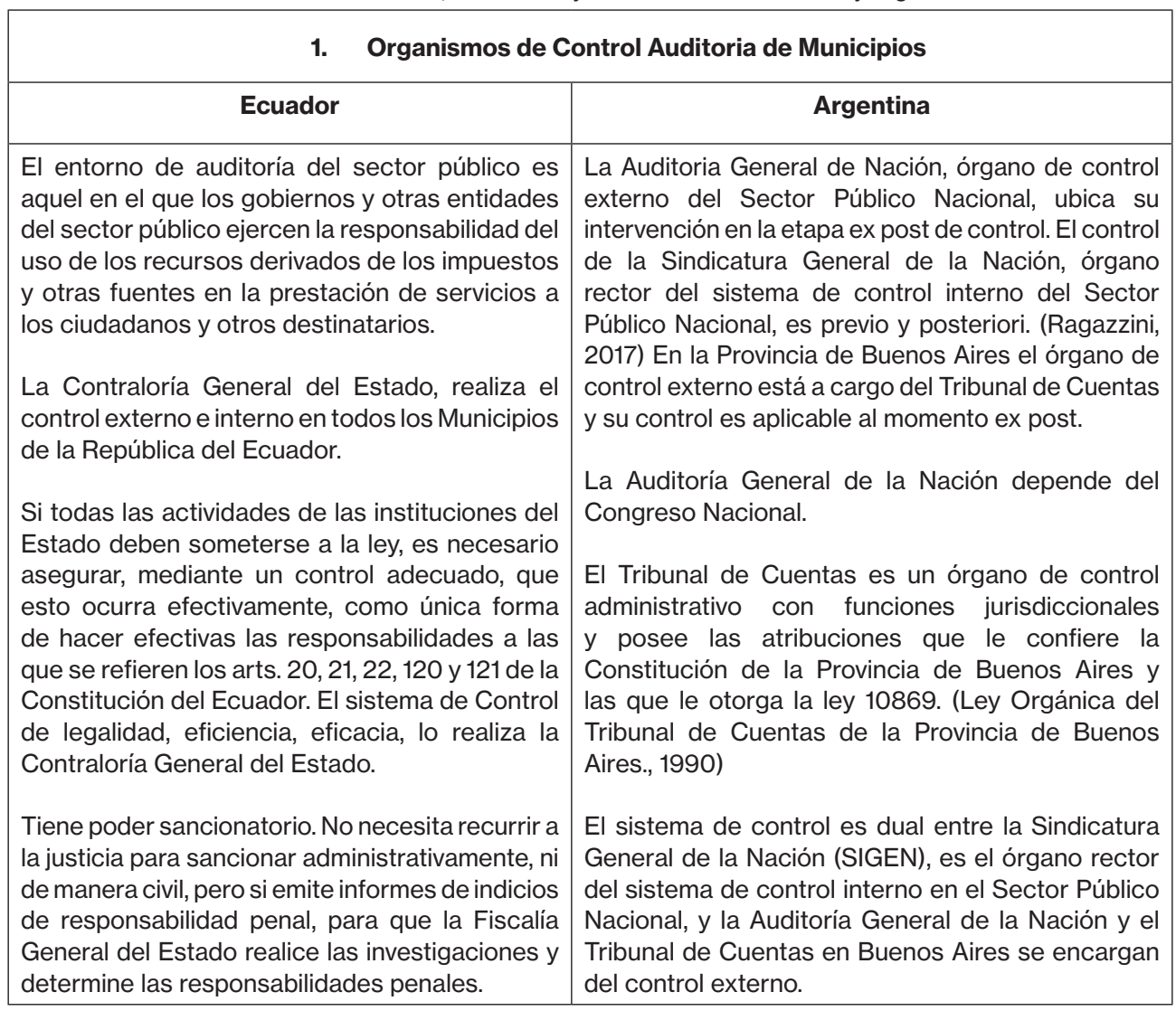




\begin{tabular}{|l|l|}
\hline \multicolumn{2}{|c|}{1 Organismos de Control Auditoria de Municipios } \\
\hline \multicolumn{1}{|c|}{ Ecuador } & \multicolumn{1}{c|}{ Argentina } \\
\hline $\begin{array}{l}\text { La máxima Autoridad del control público es el } \\
\text { Contralor General del Estado, quien es elegido } \\
\text { por concurso de méritos y oposición. }\end{array}$ & $\begin{array}{l}\text { El Honorable Tribunal de cuentas, posee poder } \\
\text { jurisdiccional impropio, porque a partir de lo } \\
\text { dispuesto por la Constitución Nacional, el Poder } \\
\text { Jurisdiccional corresponde al Poder Judicial, el }\end{array}$ \\
$\begin{array}{l}\text { El Contralor y Subcontralor serán electos } \\
\text { por un período de cinco años y no podrán ser } \\
\text { reelectos para el período subsiguiente. Art. 154 } \\
\text { (Constitución de la República del Ecuador, 2008) }\end{array}$ & $\begin{array}{l}\text { impropio porque: a) no puede imponer penas } \\
\text { privativas de la libertad y b) sus decisiones son } \\
\text { recurribles ante la justicia. }\end{array}$ \\
\hline
\end{tabular}

Fuente: Elaboración propia, tomada de la Constitución del Ecuador y las Leyes Orgánicas de Argentina.

En el cuadro anterior podemos ver la estructura del control interno y externo de los dos países, Ecuador por ser un país pequeño, canaliza sus acciones de control del sector público con una sola institución, la Contraloría General del Estado. Argentina posee una mayor estructura en el control interno y externo como se muestra en el cuadro 3. En los Municipios el Contador Municipal es el responsable del control interno y del Control Externo el Tribunal de Cuentas y Consejos Deliberantes.

Integrar cada uno de los procesos objeto de revisión en entidades públicas o privadas permite establecer responsabilidades en cada uno de los niveles de las entidades.

"El control sobre el cumplimiento de las normas y los programas de las reparticiones corresponde, en primer lugar, a los titulares de esos ministerios y organismos descentralizados, pero también a otras oficinas de control que tienen autonomía y son, o deberían ser, independientes de los cuerpos que deben monitorear". (Clarín, 2007).

La auditoría del sector público ayuda a crear condiciones adecuadas y refuerza la expectativa de que las entidades del sector y los servidores públicos desempeñarán sus funciones de manera efectiva, eficiente, ética y de conformidad con las leyes y regulaciones aplicables.

En general, la auditoría del sector público se puede describir como un proceso sistemático de obtención objetiva y evaluación de evidencia para determinar si la información o las condiciones reales se ajustan a los criterios establecidos (Amershi, 1986)

La auditoría del sector público es esencial ya que proporciona a los órganos legislativos y de supervisión, a los encargados del gobierno y al público en general información y evaluaciones independientes y objetivas sobre la administración y el desempeño de las políticas, programas u operaciones del gobierno. (ISSAI, 2017)

\section{RESULTADOS}

Se realizó un análisis comparativo entre Ecuador y Argentina, delimitando la provincia de Buenos aires, enfocando el Control en los Municipios, resumida en el siguiente cuadro: 


\begin{tabular}{|c|c|c|}
\hline $\begin{array}{l}\text { Control } \\
\text { Púbico }\end{array}$ & Ecuador & Argentina \\
\hline Constitución & $\begin{array}{l}\text { Constitución de la Republica del } \\
\text { Ecuador } \\
\text { Art. 204.- El pueblo es el mandante y } \\
\text { primer fiscalizador del poder público, en } \\
\text { ejercicio de su derecho a la participación. } \\
\text { El Consejo de Participación Ciudadana y } \\
\text { Control Social, la Defensoría del Pueblo, } \\
\text { la Contraloría General del Estado y } \\
\text { las superintendencias, de acuerdo al } \\
\text { Art. 205.- Los representantes de las } \\
\text { entidades forman parte de la Función de } \\
\text { Transparencia y Control Social ejercerán } \\
\text { sus funciones durante un período de cinco } \\
\text { años, tendrán fuero de Corte Nacional y } \\
\text { estarán sujetos al enjuiciamiento político } \\
\text { de la Asamblea Nacional. (Constitución de } \\
\text { la República del Ecuador, 2008) }\end{array}$ & $\begin{array}{l}\text { Constitución Nacional República Argentina } \\
\text { Art. 5.- Cada provincia dictará para sí una Constitución } \\
\text { bajo el sistema representativo republicano, de } \\
\text { acuerdo con los principios, declaraciones y } \\
\text { garantías de la Constitución Nacional. Asegurando } \\
\text { la autonomía municipal y reglando su alcance } \\
\text { y contenido en el orden institucional, político, } \\
\text { administrativo, económico y financiero. } \\
\text { Constitución de la Provincia de Buenos Aires } \\
\text { Art. } 190 \text { - La administración estará a cargo de una } \\
\text { municipalidad, compuesta de un departamento } \\
\text { ejecutivo unipersonal y un departamento deliberativo, } \\
\text { cuyos miembros, que no podrán ser menos de seis } \\
\text { ni más de veinticuatro, durarán cuatro años en sus } \\
\text { funciones. (Constitución de la Provincia de Buenos } \\
\text { Aires, 1994) }\end{array}$ \\
\hline $\begin{array}{l}\text { Organismos } \\
\text { encargados } \\
\text { del Control }\end{array}$ & $\begin{array}{l}\text { Contraloria General del Estado } \\
\text { Art. 211.- La Contraloría General del } \\
\text { Estado es un organismo técnico } \\
\text { encargado del control de la utilización de } \\
\text { los recursos estatales, y la consecución } \\
\text { de los objetivos de las instituciones. } \\
\text { Art. 212.- Serán funciones: } \\
\text { 1. Dirigir el sistema de control } \\
\text { administrativo que se compone de } \\
\text { auditoría interna, auditoría externa y } \\
\text { del control interno de las entidades } \\
\text { del sector público y de las entidades } \\
\text { privadas que dispongan de recursos } \\
\text { públicos. } \\
\text { 2. Determinar } \\
\text { administrativas y civiles culposas e } \\
\text { indicios de responsabilidad penal. } \\
\text { 3. Expedir la normativa para el } \\
\text { cumplimiento de sus funciones. } \\
\text { 4. Asesorar a los órganos y entidades } \\
\text { del Estado cuando se le solicite. } \\
\text { (Contraloría General del Estado, 2014) }\end{array}$ & $\begin{array}{l}\text { Auditoría General de la Nación } \\
\text { El objetivo primario de la Auditoría General de la } \\
\text { Nación es contribuir a que se adopten decisiones } \\
\text { eficaces, económicas y eficientes en materia de } \\
\text { gastos e ingresos públicos. (Ley 24.156, 1992): } \\
\text { "Es materia de su competencia el control externo } \\
\text { posterior de la gestión presupuestaria, económica, } \\
\text { financiera, patrimonial, legal, (...) (Ley 24.156, 1992) } \\
\text { Administración financiera y el sistema de control } \\
\text { de la administración general del estado provincial, } \\
\text { aplicado a la Provincia de Buenos Aires } \\
\text { Art 3.- El sistema de control estará a cargo de la } \\
\text { Fiscalía de Estado, la Contaduría General de la } \\
\text { Provincia y el Tribunal de Cuentas de la Provincia. } \\
\text { Art.103.- La Contaduría General de la Provincia } \\
\text { ejercerá el control interno de la gestión económico- } \\
\text { financiera del Sector Público Provincial y de los } \\
\text { Poderes Legislativo y Judicial. } \\
\text { Art. 102 La fiscalía de Estado tiene el control de } \\
\text { legalidad de los actos administrativos, conforme a } \\
\text { la Constitución de la Provincia de Buenos Aires y su } \\
\text { respectiva ley orgánica. (Administración Financiera y } \\
\text { el Sistema de Control de la Administración General } \\
\text { del estado Provincial, 2007) } \\
\text { Ley Orgánica del Honorable Tribunal de Cuentas } \\
\text { de la Provincia De Buenos Aires } \\
\text { Art. 1.- El Tribunal de Cuentas es un órgano de control } \\
\text { administrativo con funciones jurisdiccionales y posee } \\
\text { las atribuciones que le confiere la Constitución de la } \\
\text { Provincia y las que le otorga esta ley. Corresponde } \\
\text { al órgano de Control Externo, derivado, tanto del } \\
\text { Gobierno de la Provincia de Buenos Aires, como de } \\
\text { los Municipios de toda la provincia. Dado que en el } \\
\text { Régimen Municipal, el órgano de control interno es } \\
\text { el Contador Municipal. (Ley Orgánica del Honorable } \\
\text { Tribunal de Cuentas de la Provincia De Buenos Aires, } \\
\text { 10869, 1992) }\end{array}$ \\
\hline
\end{tabular}




\begin{tabular}{|c|c|c|}
\hline $\begin{array}{l}\text { Control } \\
\text { Púbico }\end{array}$ & Ecuador & Argentina \\
\hline $\begin{array}{l}\text { Responsables } \\
\text { del control } \\
\text { Interno } \\
\text { Municipal }\end{array}$ & $\begin{array}{l}\text { Ley Orgánica de Contraloría General del } \\
\text { estado. Art. } 12 \text { Tiempos de control } \\
\text { Tiempos de control.- El ejercicio del } \\
\text { control interno se aplicará en forma } \\
\text { previa, continua y posterior. } \\
\text { La Ley no define quien es el responsable } \\
\text { de los controles internos y de medir } \\
\text { la eficiencia, economía y eficiencia de } \\
\text { los municipios. (Contraloría General } \\
\text { del Estado, 2014) Menciona que todos } \\
\text { los servidores de las entidades son } \\
\text { responsables del control interno. } \\
\text { (Contraloría General del Estado, 2014) } \\
\text { Es fundamentalmente la consecuencia } \\
\text { de la actitud asumida por la alta dirección } \\
\text { y por el resto de las servidoras y } \\
\text { servidores, con relación a la importancia } \\
\text { del control interno y su incidencia sobre } \\
\text { las actividades y resultados. (Contraloría } \\
\text { General del Estado, 2014) } \\
\text { La norma define que todos los servidores } \\
\text { de la entidad municipal son responsables } \\
\text { del control interno, pero no establece } \\
\text { quien es el responsable del control } \\
\text { interno institucional. }\end{array}$ & $\begin{array}{l}\text { Ley orgánica de las Municipalidades } \\
\text { Art. 180.- Los cargos de contador, tesorero y jefe } \\
\text { de compras son incompatibles con cualquier otra } \\
\text { función municipal y reciprocamente. } \\
\text { Art. 183.- El Intendente podrá autorizar a extender } \\
\text { órdenes de compras y de pagos que no excedan del } \\
\text { monto establecido. } \\
\text { Art. 186.- El contador municipal, deberá observar } \\
\text { las transgresiones señalando los defectos de } \\
\text { la resolución que ordene el gasto, pero si el } \\
\text { Departamento Ejecutivo insistiera en ella por } \\
\text { escrito, le dará cumplimiento quedando exento de } \\
\text { responsabilidad. (Reforma de la Administración } \\
\text { Financiera en el Ambito Municipal, decreto } 2980 \text {., } \\
2000 \text { ) } \\
\text { Reforma Administración Financiera en el Ámbito } \\
\text { Municipal } \\
\text { Art. 39.- El Contador General será personal y } \\
\text { funcionalmente responsable por la exactitudy claridad } \\
\text { de los estados contables que elabore la Contaduria } \\
\text { General del Municipio en el marco de lo dispuesto por } \\
\text { la Ley Orgánica de las Municipalidades y las presentes } \\
\text { disposiciones. (Reforma de la Administración } \\
\text { Financiera en el Ámbito Municipal, 2000) } \\
\text { El cargo de Contador Municipal forma parte del } \\
\text { financiamiento del personal en el Presupuesto } \\
\text { Municipal, en cuanto al Tribunal de Cuentas de la } \\
\text { Provincia de Buenos Aires (control externo) tiene } \\
\text { asignación presupuestaria en la Ley de Presupuesto } \\
\text { anual de la Provincia de Buenos Aires. }\end{array}$ \\
\hline $\begin{array}{l}\text { Control } \\
\text { Externo }\end{array}$ & $\begin{array}{l}\text { Ley Orgánica de la Contraloría General } \\
\text { del Estado } \\
\text { Art. 12.- La Contraloría General del Estado } \\
\text { será la responsable del control posterior a } \\
\text { través de las unidades de auditoría interna } \\
\text { y externa, se aplicará a las actividades } \\
\text { institucionales, con posterioridad a su } \\
\text { ejecución. } \\
\text { La Contraloría General del Estado, } \\
\text { cuando así lo determinen podrá efectuar } \\
\text { la auditoría gubernamental, mediante la } \\
\text { contratación de compañías privadas de } \\
\text { auditoría externa e independiente. }\end{array}$ & $\begin{array}{l}\text { Auditoría General de la Nación } \\
\text { Organismo de asistencia técnica del Congreso, } \\
\text { con autonomía funcional, asiste técnicamente } \\
\text { al Congreso de la Nación Argentina en el control del } \\
\text { estado de las cuentas del sector público. No controla } \\
\text { a Municipios (Ley 24.156, 1992) } \\
\text { Ley Orgánica del Honorable Tribunal de Cuentas. } \\
\text { Provincia De Buenos Aires } \\
\text { Art. 45.- El Tribunal de cuentas de la Provincia } \\
\text { de Buenos Aires queda facultado para actuar } \\
\text { como Auditor Externo de Organismos Financieros } \\
\text { Nacionales o Internacionales en las operaciones } \\
\text { de crédito que los mismos realicen en jurisdicción } \\
\text { territorial de la Provincia. Controla Municipios. }\end{array}$ \\
\hline $\begin{array}{l}\text { Encargados } \\
\text { del Control } \\
\text { Interno } \\
\text { dentro de los } \\
\text { Municipios }\end{array}$ & $\begin{array}{l}\text { Normas de Control Interno de la } \\
\text { Contraloria General del Estado } \\
\text { Art. 6.- Componentes del Sistema. } \\
\text { La ejecución del sistema de control, } \\
\text { fiscalización y auditoría del Estado se } \\
\text { realizará por medio de: 1.- El control } \\
\text { interno, que es de responsabilidad } \\
\text { administrativa de cada una de las } \\
\text { instituciones del Estado a las que se } \\
\text { refiere el artículo } 2 \text { de esta Ley; y, 2.- El } \\
\text { control externo que comprende: a. El } \\
\text { que compete a la Contraloría General } \\
\text { del Estado; y, b. El que ejerzan otras } \\
\text { instituciones de control del Estado en el } \\
\text { ámbito de sus competencias. (Contraloría } \\
\text { General del Estado, 2014) } \\
\text { El cargo de auditor interno formó parte } \\
\text { del presupuesto anual hasta el año } 2018 \\
\text { de la Contraloría General del Estado. }\end{array}$ & $\begin{array}{l}\text { Reforma Administración Financiera en el Ámbito } \\
\text { Municipal } \\
\text { Art. 39.- El Contador General será personal y } \\
\text { funcionalmente responsable por la exactitud y } \\
\text { claridad de los estados contables que elabore la } \\
\text { Contaduria General del Municipio en el marco de lo } \\
\text { dispuesto por la Ley Orgánica de las Municipalidades } \\
\text { y las presentes disposiciones. (Reforma de la } \\
\text { Administración Financiera en el Ambito Municipal, } \\
2000 \text { ) } \\
\text { El cargo de Contador Municipal forma parte del } \\
\text { financiamiento del personal en el Presupuesto } \\
\text { Municipal, en cuanto al Tribunal de Cuentas de la } \\
\text { Provincia de Buenos Aires (control externo) tiene } \\
\text { asignación presupuestaria en la Ley de Presupuesto } \\
\text { anual de la Provincia de Buenos Aires. }\end{array}$ \\
\hline
\end{tabular}




\begin{tabular}{|c|c|c|}
\hline $\begin{array}{l}\text { Control } \\
\text { Púbico }\end{array}$ & Ecuador & Argentina \\
\hline $\begin{array}{l}\text { Situación de } \\
\text { servidores } \\
\text { a cargo de } \\
\text { los controles } \\
\text { clave }\end{array}$ & $\begin{array}{l}\text { Ley Orgánica de los Servidores Públicos } \\
\text { Art.- } 65 \text {. De libre remoción, la máxima } \\
\text { autoridad tiene la potestad de prescindir } \\
\text { de sus servicios. Director Financiero, } \\
\text { contador, Director o Jefe de Compras. }\end{array}$ & $\begin{array}{l}\text { Ley orgánica de las Municipalidades } \\
\text { Art. 213.- El personal estable de los organismos } \\
\text { descentralizados será designado y removido por } \\
\text { el Departamento Ejecutivo de la Municipalidad a } \\
\text { propuesta de la Dirección de aquéllos. El contador es } \\
\text { el responsable del control interno en los Municipios y } \\
\text { es un funcionario de carrera. }\end{array}$ \\
\hline $\begin{array}{l}\text { Funciones } \\
\text { con respecto } \\
\text { al control } \\
\text { de Auditoría } \\
\text { Interna }\end{array}$ & $\begin{array}{l}\text { Ley Orgánica de la Contraloría General } \\
\text { del Estado } \\
\text { Art. 14.- Las instituciones del Estado, } \\
\text { contarán con una Unidad de Auditoria } \\
\text { Interna, cuando se justifique, que } \\
\text { dependerá técnica y administrativamente } \\
\text { de la Contraloria General del Estado. } \\
\text { El personal auditor, sera nombrado, } \\
\text { removido o trasladado por el Contralor } \\
\text { General del Estado y las remuneraciones } \\
\text { que corresponden a las máximas } \\
\text { autoridades de las Unidades de Auditoría } \\
\text { Interna de los Gobiernos Autónomos } \\
\text { Descentralizados serán cubiertas por la } \\
\text { Contraloría General del Estado. } \\
\text { Evalúa el control interno efectuado } \\
\text { (posterior) no tienen injerencia alguna en } \\
\text { procedimientos internos. } \\
\text { Art. 15.- Independencia. Los auditores } \\
\text { de esta unidad actuarán individual } \\
\text { o colectivamente, con criterio } \\
\text { independiente respecto a la operación } \\
\text { o actividad auditada y no intervendrán } \\
\text { en la autorización o aprobación de los } \\
\text { procesos financieros, administrativos, } \\
\text { operativos y ambientales. } \\
\text { Art. } 16 .- \text { Coordinación de labores. La } \\
\text { Contraloría General del Estado prestará } \\
\text { su asesoría y asistencia técnica a las } \\
\text { unidades de auditoría interna de gestión } \\
\text { y orientará y coordinará la preparación de } \\
\text { su Plan Anual de Trabajo, presentado a la } \\
\text { Contraloría General del Estado hasta el } \\
\text { 30 de septiembre de cada año. } \\
\text { Art. 9.- Concepto y elementos del Control } \\
\text { Interno. El control interno constituye } \\
\text { un proceso aplicado por la máxima } \\
\text { autoridad, la dirección y el personal } \\
\text { de cada institución que proporciona } \\
\text { seguridad razonable de que se protegen } \\
\text { los recursos públicos y se alcancen los } \\
\text { objetivos institucionales. } \\
\text { Constituyen elementos del controlinterno: } \\
\text { el entorno de control, la organización, la } \\
\text { idoneidad del personal; y, la corrección } \\
\text { oportuna de las deficiencias de control. } \\
\text { El control interno será responsabilidad } \\
\text { de cada institución del Estado, y tendrá } \\
\text { como finalidad primordial crear las } \\
\text { condiciones para el ejercicio del control } \\
\text { externo a cargo de la Contraloria General } \\
\text { del Estado. }\end{array}$ & $\begin{array}{l}\text { Ley Orgánica de las Municipalidades de la Provincia } \\
\text { de Buenos Aires } \\
\text { Art. } 186 .- \text { El contador municipal no dará curso a } \\
\text { resoluciones que ordenen gastos infringiendo } \\
\text { disposiciones constitucionales, legales de } \\
\text { ordenanzas o reglamentarias. Deberá observar } \\
\text { las transgresiones señalando los defectos de } \\
\text { la resolución que ordene el gasto, pero si el } \\
\text { Departamento Ejecutivo insistiera en ella por } \\
\text { escrito, le dará cumplimiento quedando exento de } \\
\text { responsabilidad. Esta se imputará a la persona del } \\
\text { Intendente. } \\
\text { Art. 188.- El contador municipal no podrá ser } \\
\text { separado de su cargo, sin acuerdo del Concejo } \\
\text { Deliberante. } \\
\text { Art. } 187 \text { : Esta ley asegura al contador el amparo } \\
\text { de sus derechos de funcionario en tanto actúe } \\
\text { de conformidad con las. En caso contrario, el } \\
\text { Tribunal de Cuentas podrá declararlo personal o } \\
\text { solidariamente responsable de los daños, perjuicios } \\
\text { y otras consecuencias emergentes de sus actos de } \\
\text { incumplimiento e inhabilitarlo por el tiempo que la } \\
\text { sentencia fije. (Ley Orgánica de las Municipalidades } \\
\text { de la Provincia de Buenos Aires, 1958) } \\
\text { Art. 9.- La contaduria responsable del control } \\
\text { interno tiene dentro de sus funciones Intervenir en la } \\
\text { preparación del proyecto de presupuesto de gastos } \\
\text { y cálculo de recursos. } \\
\text { b) Llevar actualizada la contabilidad del movimiento } \\
\text { de fondos, patrimonial y de presupuesto y practicar } \\
\text { balances en tiempo oportuno para su publicación. } \\
\text { c) Intervenir en todos los expedientes de crédito } \\
\text { suplementario, ampliaciones y deducciones del } \\
\text { presupuesto de gastos dictaminando acerca } \\
\text { del carácter legal de tales operaciones y de las } \\
\text { posibilidades financieras de las mismas. } \\
\text { d) Intervenir previamente todo ingreso o egreso } \\
\text { de fondos, pudiendo en el primer caso adoptar los } \\
\text { medios técnicos necesarios para tal fin. } \\
\text { e) Practicar arqueos mensuales de Tesorería, } \\
\text { conciliar los saldos bancarios con los municipales } \\
\text { y denunciar inmediatamente toda falla al D.E. El } \\
\text { acta de arqueo practicado al cierre del ejercicio } \\
\text { se transcribirá en el libro Caja a continuación del } \\
\text { último asiento registrado en el mismo, firmando } \\
\text { para constancia los funcionarios. (Reglamento de } \\
\text { Contabilidad de Municipios de Buenos Aires, } 2004 \text { ) }\end{array}$ \\
\hline
\end{tabular}




\begin{tabular}{|c|c|c|}
\hline $\begin{array}{l}\text { Control } \\
\text { Púbico }\end{array}$ & Ecuador & Argentina \\
\hline $\begin{array}{l}\text { Máxima } \\
\text { Autoridad }\end{array}$ & $\begin{array}{l}\text { Ley Orgánica de la Contraloría General } \\
\text { del Estado } \\
\text { Art. 32.- El Contralor General del Estado } \\
\text { es la máxima autoridad de control } \\
\text { gubernamental y auditoria de la gestión } \\
\text { pública. Designa al auditor interno de un } \\
\text { municipio y remueve de ser necesario } \\
\text { existiendo o no, una falta del servidor. }\end{array}$ & $\begin{array}{l}\text { Reglamento de Contabilidad de Municipios de } \\
\text { Buenos Aires } \\
\text { Art. 6.- Las máximas autoridades de los Municipios } \\
\text { son asesorados por el contador Municipal quien } \\
\text { es el responsable de control interno y su cargo es } \\
\text { incompatible con el desempeño de cualquier otra } \\
\text { función en la Municipalidad, no puede ser separado } \\
\text { sin acuerdo del Consejo deliberante, con petición } \\
\text { fundamentada, pudiendo el Contador tener derecho } \\
\text { a la defensa, pudiendo requerirse dictamen del } \\
\text { Tribunal de Cuentas. } \\
\text { Art. } 8^{\circ} \text { - El Contador deberá observar por escrito, en } \\
\text { el mismo documento toda orden, decreto, resolución, } \\
\text { disposición o comunicación, cuyo cumplimiento } \\
\text { fuese violatorio de las disposiciones legales o } \\
\text { reglamentarias concernientes a la materia que le } \\
\text { compete. Su observación interrumpirá el curso } \\
\text { de aquellos, pero el Contador deberá cumplirlos } \\
\text { y quedará exento de responsabilidad cuando el } \\
\text { Departamento Ejecutivo formule insistencia por } \\
\text { escrito. (Reglamento de Contabilidad de Municipios } \\
\text { de Buenos Aires, 2004) }\end{array}$ \\
\hline
\end{tabular}

Fuente: Elaboración propia, tomada de las Constituciones y Leyes orgánicas de Ecuador y Argentina.

Argentina mediante decreto No.72/2018, modifica el artículo 102 que dice: "que los Auditores Internos Titulares del Sector Público Nacional, tal como se encuentra definido en el artículo 8 de la citada Ley № 24.156 -y su reglamentario del Decreto № 1344/2007- serán designados por la SINDICATURA GENERAL DE LA NACIÓN, la cual, establece requisitos necesarios para el desempeño del cargo". (Boletín Oficial de la República de Argentina, 2018). Esta misma Ley aprobó el perfil y responsabilidades del Auditor Interno Titular, descriptos en el Anexo I de la presente (IF-2018-23202675-APN-SIGEN), de todas las Unidades de Auditoría Interna que integran el Sector Público Nacional con el alcance establecido en el artículo $8^{\circ}$ de la Ley $N^{\circ} 24.156$ y su reglamentario del Decreto $N^{\circ} 1344 / 2007$.

En Ecuador para el cargo de auditores internos rige la Ley Orgánica de la Contraloría General del estado donde menciona que Art. 14.- Auditoría Interna. (Reformado por el Art. 2 de la Ley s/n, R.O. 1S, 11VIII2009). Las instituciones del Estado, contarán con una Unidad de Auditoría Interna, cuando se justifique,

que dependerá técnica y administrativamente de la Contraloría General del Estado, el auditor, será nombrado, removido o trasladado por el Contralor general del Estado y las remuneraciones y gastos para el funcionamiento que corresponden a las máximas autoridades de las Unidades de Auditoría Interna de los Gobiernos Autónomos Descentralizados serán cubiertas por la Contraloría General del Estado. (Contraloría General del Estado, 2014).

Las actividades del auditor no detienen ningún acto administrativo, ya que su independencia de los procesos municipales se enfoca en realizar exámenes especiales 
que la Contraloría General del Estado lo disponga por medio de una orden de trabajo y una planificación anual. Hasta octubre de 2018, los Auditores Generales, Directores de las Unidades de Auditoría Interna que se encontraban en el presupuesto de la Contraloría, cesaron en sus funciones a través de acción de personal dispuesto por el Contralor en los Municipios, basado en los artículos 31, número 23, y 35 de 'expedir y mantener actualizado el reglamento orgánico funcional, que contendrá la estructura administrativa y las funciones de las respectivas unidades para el cumplimiento de los fines y objetivos de la entidad de control'; (Contraloría General del Estado, 2014). Los Gobiernos Autónomos Descentralizados tienen la obligación de estructurar su sistema de Control interno basados en medición de sus funciones a través de indicadores que pueda reflejar la situación actual de las administraciones.

A pesar del ajuste presupuestario de la Contraloría no se observaron ajustes a la estructura de los Municipios del Ecuador con respecto a las Unidades de Auditorías Internas, con respecto a las funciones de auditoría interna, plasmados en las leyes, y demás orgánicos estructurales y funcionales.

\section{CONCLUSIONES}

- Las Constituciones de los dos países, establecen los organismos de control y sus competencias hacia los Municipios, sin embargo, en las funciones del control interno en Ecuador no se establece quien tiene la responsabilidad del mismo.

- En los Municipios de Ecuador los Auditores Internos son designados por el Contralor General del Estado, sus remuneraciones son canceladas por la Contraloría General del Estado, y su estado laboral es de libre remoción, dependiendo técnica y administrativamente del ente de control. En argentina son los contadores funcionarios de carrera que necesitan la aprobación de un consejo deliberante para cesar de sus funciones.

- A partir de los resultados obtenidos en el estudio, es posible afirmar que, en los municipios de ambos países, las actividades y procedimientos dirigidos hacia el control interno se definen en marcos legales de aplicación obligatoria, presentados a través de normas internas, reglamentos, manuales, disposiciones, entre otros, cuya inobservancia acarrea una responsabilidad administrativas, civiles y penales.

- En Ecuador La norma define que todos los servidores de la entidad municipal son responsables del control interno, pero no establece quien es el 
responsable del control interno institucional. En Argentina el Contador es el responsable de control interno, y es servidor de carrera.

- En Ecuador, el control se basa en la utilización de los recursos estatales, y la consecución de los objetivos de las instituciones. Argentina directamente mantiene un sistema de control interno normativo, financiero, económico y de gestión sobre sus propias operaciones, comprendiendo la práctica del control previo y posterior.

- El control interno y el control externo en Ecuador son realizados por una única institución, en Argentina, los controles internos y externos, además de la diferenciación de las provincias, son realizados por diferentes entidades de la estructura del control público, lo que podría ser una fortaleza para minimizar los riesgos en la administración pública, especialmente en municipios.

- Es necesario que Ecuador dé importancia a la responsabilidad del control interno con enfoque legal, ya que, es clave para el éxito de la administración municipal, la misma que genera confianza en el accionar y minimiza el riesgo.

\section{BIBLIOGRAFÍA}

Administración Financiera y el Sistema de Control de la Administración General del estado Provincial. (2007). Art.103 El Sistema de Control. Buenos Aires.

Amershi. (20 de Abril de 1986). Discussion of "A model of standard setting in auditing. En Amin, \& A. Amershi, Discussion of "A model of standard setting in auditing (pág. pag. 48). Canadá: Contemporary Accounting Research.

Boletín Oficial de la República de Argentina. (16 de 05 de 2018). Argentina Presidencia. Obtenido de Sindicatura General de la Nación: https://www.boletinoficial.gob.ar

Clarín. (21 de 08 de 2007). Modelo de evaluación de Control Interno en la Administración Pública Estatal. Editorial Clarín, págs. https://www.clarin.com/opinion/importancia-controles_0_BkAzell1CYx. html.

Código Orgánico de Organización Territorial, Autonomía y Descentraliziación de los Gobiernos Autónomos Descentralizados Del Ecuador. (2010). AUTONOMÍA. QUITO.

Constitución de la Provincia de Buenos Aires. (13 de Septiembre de 1994). REGIMEN MUNICIPAL. Obtenido de Constitución de la Provincia de Buenos Aires: https://www.htc.gba.gov.ar/images/ legislacion/ConstitucionBsAs.pdf

Constitución de la República del Ecuador. (20 de Octubre de 2008). Constitución del Ecuador. Obtenido de Defensoría del Pueblo: https://biblioteca.defensoria.gob.ec/handle/37000/2726

Contraloría General del Estado. (2014). Norma 200 Ambiente de Control.

Contraloría General del Estado. (2014). Ley Organica de la Contraloria General del Estado. Ecuador. 
Contraloría General del Estado. (2014). Normas de Control Interno. Quito.

Estudio Comparativo de las leyes de Régimen Local. (2011). Comisión de Desarrollo Municipal Senado de la República. Parlatino, 1-64.

Gismano, Y., Ferreira, C., Aispuro, G., Scoponi, L., \& Iriarti, F. (2019). Control y transparencia en el sector público argentino. CEA Vol 3 No2, 12.

ISSAI. (2017). La Auditoría en el sector público. Colombia.

Iturburo, M. S. (2004). MUNICIPIOS ARGENTINOS, Potestades y Restricciones constitucionales para un nuevo modeo de Gestión Local. Buenos Aires : INAP.

Iturburu, Mónica Silvana. (2004 2 Edición). Municipios Argentinos, Potestades y Restricciones Constitucionales. INSTITUTO NACIONAL DE LA ADMINISTRACIÓN PÚBLICA, Dirección Nacional de Estudios y Documentación, Direccion de Estudios e Investigaciones, 155. Obtenido de http:// municipios.unq.edu.ar/modules/mislibros/archivos/municipios_argentinos.pdf

Ley 24.156. (1992). Administracion financiera y de los sistemas de control del sector publico nacional. Buenos Aires.

Ley de Administración Financiera y de los Sistemas de Control del Sector Público Nacional. (Ley 24.156 B.O. 29/10/1992).).

Ley Orgánica de las Municipalidades de la Provincia de Buenos Aires. (1958). Decreto 6769. Buenos Aires.

Ley Orgánica del Honorable Tribunal de Cuentas de la Provincia De Buenos Aires, 10869. (1992). Tribunal de Cuentas. Buenos Aires.

Ley Orgánica del Tribunal de Cuentas de la Provincia de Buenos Aires. (1990). Articulo 1.- Tribunal de Cuentas. Buenos Aires.

Oszlak, O. (2013). Gobierno Abierto hacia un nuevo paradigma. Red de Gobierno electrónico America Latina y el Caribe RED GEALC.

Ragazzini, P. (2017). El Sistema de Control Público de la Comuna de Alcorta. Rosario.

Reforma de la Administración Financiera en el Ámbito Municipal. (2000). Articulo 39. Buenos Aires.

Reforma de la Administración Financiera en el Ambito Municipal, decreto 2980. (2000). Capitulo III. Buenos Aires.

Reglamento de Contabilidad de Municipios de Buenos Aires. (2004). La Contaduría. Buenos Aires.

The Dialogue. (7 de julio de 2016). Obtenido de Cinco reflexiones sobre las reformas políticas en América Latina: https://www.thedialogue.org/blogs/2016/07/cinco-reflexiones-sobre-las-reformaspoliticas-en-america-latina/?lang=es 


\section{SOBRE O ORGANIZADOR}

Leinig Antonio Perazolli possui graduação em Engenharia Química pela Universidade Estadual de Maringá (1986), mestrado em Engenharia Química pela Universidade Estadual de Campinas (1991) e doutorado em Química pela Universidade Federal de São Carlos (1996). Atualmente é professor Livre Docente III do Instituto de Química - Unesp / Araraquara. Tem experiência na área de Engenharia de Materiais e Metalúrgica com estudos de Sinterização de Cerâmicos e obtenção de Foto catalisadores Cerâmicos e na área de História da Ciência com ênfase em Química e Engenharia Química. Atua na área de pesquisa nos seguintes temas: óxido de titânio, óxido de estanho, sinterização, voltados para a foto catálise e cerâmicas eletrônicas. $\mathrm{Na}$ área de extensão universitária desenvolve trabalhos sobre História da Ciência e da Engenharia Química e sobre a Química das Coisas. Leciona disciplinas na área de Química Tecnológica, Engenharia Química e História da Ciência. 


\section{ÍNDICE REMISSIVO}

A

Absorción 106, 107, 110, 142, 171, 176, 178, 180, 181, 182, 183, 184, 188

Aceite $147,148,149,150,151,153,154,155,156,157,158,159,160,161,162,163,164,165$, $166,167,169$

Aguacate $147,148,149,150,151,153,154,155,156,157,158$

Aislación térmica 114, 115, 117, 120, 131, 132

Análisis 1, 2, 5, 7, 8, 9, 10, 13, 14, 16, 20, 23, 24, 26, 30, 32, 69, 86, 87, 89, 90, 95, 116, 129, $131,134,136,137,138,139,141,142,144,162,163,167,173,186,188,189$

Antimicrobiana 134, 135, 136, 148, 158, 161, 169

Apatita $186,187,188,189,191$

Aplicaciones 43, 160

A-site substitutions 227

Aspergillus niger 103, 104, 105, 111, 112, 113

Avaliação 47, 58, 59, 63, 64, 66, 67, 68, 250, 253, 255, 256, 257, 258, 259, 260, 261, 262, $264,265,268,273,278,279$

B

$\mathrm{BiFeO}_{3} 227,228,231,232,233$

Biomasa 103, 104, 106, 107, 108, 109, 110, 111, 113, 160

C

Climas cálidos 114, 117, 129, 130

Cohesión social 69

Combustiveis renováveis 214

Composición proximal 160, 168

Compresión 121, 171, 172, 173, 174, 175, 182, 183, 184

Consumidor ético 1, 2, 7, 11, 14

Consumo energético 114, 115, 116, 117, 122, 123, 124, 125, 126, 127, 128, 129, 130, 131, 217

Consumo ético 1, 2, 3, 5, 6, 7, 8, 9, 10, 11, 14, 15, 16

Consumo responsable 1

Contaminación Difusa 18, 19, 22, 33

Control interno 89, 92, 93, 94, 95, 96, 97, 98, 99, 100, 101, 102

Cuprita $134,136,137,138,139,140,141,142,143,144,145$ 
D

Densidad 166, 171, 175, 177, 179, 180, 182, 183, 193, 197, 206, 207, 211, 238, 239, 243, 245, 246

Deposição eletroforética 234, 235, 237, 240, 248

Desarrollo 8, 18, 20, 21, 32, 37, 39, 40, 41, 42, 43, 46, 69, 70, 75, 76, 77, 84, 85, 86, 87, 88, $90,91,102,149,153,154,155,167,170,171,172,176,179,187$

Difusão 207, 234, 235, 241, 243, 245, 254

Difusão de Cromo 235

$E$

Ecosistemas de Emprendimiento 36, 37, 38

Emancipatória 47, 58, 59, 64, 66, 68

Emprendimiento $36,37,38,39,40,41,42,43,44,45$

Espectroscopia 200, 251, 253, 268

Etanol 214, 215, 216, 217, 221, 222, 224, 225

Ética del consumo 1

Extração líquido-líquido 214, 218, 221, 222, 223, 224, 225

$\mathbf{F}$

Ferric properties 227

Flotación 186, 187, 188, 189, 190, 191

G

Glioma 250, 251, 252, 253, 254, 267, 268, 269

Glioma Astrocítico 251

I

Imagem de Perfusão 251

M

Materiais compósitos com matriz de alumínio 193, 194

Metales pesados 103, 104, 105, 106, 107, 108, 109, 110, 111

Moringa oleifera Lam 159, 160, 161, 162, 163, 164, 165, 167, 168, 169

Municipios locales 89 
Normas $1,5,6,7,8,13,14,15,89,95,97,100,102$

O

Óxido 109, 134, 135, 136, 137, 145, 146, 196, 235

Óxido de estanho 235

$\mathbf{P}$

Percepción $6,8,9,10,11,14,15,69,70,71,74,75,76,79,81,82,83,84,87,88$

Perfusão 251, 253, 254, 255, 256, 258, 259, 261, 264, 265, 267, 268

Permeabilidade Capilar 251

Porosidad 171, 176, 177, 178, 180, 181, 182, 183, 184

Potencialidades 65, 147, 148, 149, 169

Procedimiento LU-IV 18, 19, 20, 21, 23, 27, 28, 29, 30, 31, 32

Q

Quelônios marinhos 270, 271, 275

$\mathbf{R}$

Relave 186, 188, 189, 191, 192

Remoción 98, 100, 103, 104, 105, 106, 107, 108, 109, 110

Resíduos de mineração 194

Ressonância Magnética 250, 251, 253, 254, 268

Roca $171,172,173,174,175,176,177,178,182,183,184$

S

Santander 36, 37, 41, 42, 43, 44, 45, 46, 186

Semillas 147, 155, 159, 160, 161, 162, 164, 169

SIG 18, 20, 270, 272

Sinerização Microondas Varistores 235

Sinterização 193, 194, 196, 197, 206, 207, 208, 210, 211, 234, 236, 237, 240, 241, 243, 244 , 245, 246, 249

Sistemas de Información Geográfica 19, 20

Staphylococcus aureus 134, 135, 136, 142, 144, 145, 146 
Tecnologias 47, 49, 52, 53, 57, 59, 60, 67, 68, 79, 83, 120, 145, 184

$\mathbf{U}$

Unidades de Conservação 270, 272, 273, 274, 276, 277

UNIFAC 214, 215, 218, 219, 221

Universidad compleja 69,88

Z

Zonas Vulnerables a la Contaminación por Nitrato (ZVN) 18, 19 